Review Article

\title{
Rhaphidophora aurea: A Review on Phytotherapeutic and Ethnopharmacological Attributes
}

\author{
*Kriti Saxena, Rajat Yadav, Dr. Dharmendra Solanki \\ Shri Ram Murti Smarak College of Engineering and Technology Pharmacy, Bareilly U.P, India. \\ *Corresponding author's E-mail: saxenakritisaxena@gmail.com
}

Received: 05-02-2021; Revised: 12-06-2021; Accepted: 21-06-2021; Published on: 15-07-2021. \begin{abstract}
Epipremnum aureum (Golden pothos), a naturally vari-coloured vascular plant that produces overabundance of foliage. it's among the foremost standard tropical decorative plant used as hanging basket crop. Associated in Nursing insight has been provided regarding the various styles of liana together with noble gas, Marble Queen, Jade Pothos and $\mathrm{N}$ Joy. This paper presents a review on botanic study and necessary characteristics of liana and special stress has been provided on varicolored leaves and plastids biogenesis explaining the necessary genes concerned throughout the method and numerous proteins related to it. Studies are enclosed comprising the special options of Epipremnum aureum in phytoremediation for the removal of metallic element and caesium and within the purification of air against gas. The antimicrobial activity of roots and leaf extracts of Epipremnum aureum against several microorganism strains are enclosed. It additionally presents the anti-termite activity of liana which will be controlled for cuss management. This article summarizes review meted out on many approaches to choosing honesty for drug development with the best chance of success. This review document presents a large vary of factual info regarding analysis work on honesty until date, sorted below headings: Phytochemical screening, antimicrobial, and inhibitor activity, vasoconstrictor, environmental and alternative fields.
\end{abstract}

Keywords: Rhaphidophora aurea, Pothos aureus, Antimicrobial, Sedentary, Anti-termites

QUICK RESPONSE CODE $\rightarrow$

DOI:

10.47583/ijpsrr.2021.v69i01.035

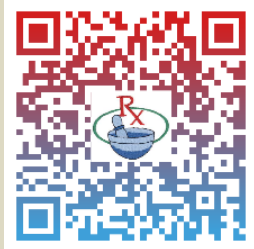

DOI link: http://dx.doi.org/10.47583/ijpsrr.2021.v69i01.035

\section{INTRODUCTION}

$\mathrm{R}$

haphidophora aurea is one of the prosaic ornamental plants. Generally, they are used for interiorscape purposes such as hanging baskets, pedestal plants, emblems of prosperity, dish gardens and small desk plants. Regularly have heart-shaped leaves that exceed rarely. It is a popular house plant in temperate regions but has also become naturalized in sub-tropical and tropical regions. It is sometimes mistakenly labeled as Philodendron in plant stores. It is most commonly known as money plant in many parts of Indian subcontinent. It rarely flowers throughout its lifespan, until and unless supplied externally with hormonal supplements. The last blooming reported was in 1964. General consideration for money plant is that it brings prosperity and concurrently help as stress busters. Researchers are having proof of relaxation of mind after touching firmly the leaves of money plant It is known as devil's ivy because of it holds a quality as it stays green even when kept in the dark or out of reach of sunshine..$^{3,7,8}$

Plants have been considered as a rich supply of conventional medication for many years because they produced a wide variety of bioactive molecules, maximum of that have been advanced as pills for the remedy of numerous diseases. In lots of developing countries, conventional medication is one of the number one fitness concern systems. ${ }^{1,2}$ Many ancient civilizations like Chinese medicine and Unani medicine have a confirm belief on treatment of plant medicine. Recent reviews indicate that approximately 13000 plant species universally are recognized to be already used as capsules. Any parts of a plant like bark, leaves, flora, roots, end result and seeds can be the prolific originators of the therapeutically active components which might also in the end affect the beneficial medicinal consequences ${ }^{3}$ Large-scale evaluation is a essential primary step for systemic isolation and identity of the lively principles of the nearby flora exploited in conventional medicine with the intention of discovering new medicine. Nowadays, the increasing bacterial resistance against antibiotics has become a concern. ${ }^{6}$ Expanding bacterial resistance is encouraging to analyze the antimicrobial task of herbs against resistant bacteria. A huge range of medicinal plants have been documented as important resource of natural antimicrobial compounds. ${ }^{7,8}$ Extract of medicinal plants helps to develop a new effective agent against bacterial resistance. ${ }^{9,10}$

\section{Plant Profile}

\section{Biological Source}

Whole plant of Rhaphidophora aurea belonging to family Araceae is having variety of significant pharmacological 
and environmental significance. This plant has suffered considerable taxonomic shuffling. It is known as Pothos aureus (Linden \& André) (1880) also; Epipremnum mooreense (Nadeaud) (1899); Scindapsus aureus (Linden \& André) Engl. (1908); Epipremnum aureum (Linden \& André) G.S.Bunting (1964) and Epipremnum pinnatum cv. Aureum. ${ }^{16,17,34}$

Epipremnum comprises of almost 15 species of slender to gigantic clinging plant. All these herbaceous evergreens are native to South East Asia and Solomon islands. Variegated clones of E. aureum (Linden and Andre) G.S. Bunting are prominent as cultivated plants globally, perhaps constituting the most prevalent civilized aroids, and the golden variegated form of this species is intermittently met with as an escape from horticulture far and wide the tropics. ${ }^{23,25,28}$

\section{Taxonomy}

Epipremnum aureum belongs to a large family Araceae having 110 genera and 2500 species in the world distributed mostly in the tropics and subtropics of both the hemispheres. ${ }^{5}$ Epipremnum Linn. is represented by more than one species in India, of which E. aureum and E. pinnatum is the most widely cultivated and best known species among the other species ${ }^{41,45}$

\author{
Kingdom - Plantae \\ Clade - Tracheophytes \\ Clade - Angiosperms \\ Clade - Monocotyledons \\ Order -Alismatales \\ Family - Araceae \\ Genus - Epipremnum \\ Species - E.aureum
}

\section{Features}

R. aureus, a persuasive clinging plant, is an equatorial creeper which can horizon vacillating heights or contend on terrain, briskly and profoundly integuments a huge expanse. It can raise promptly up the stalks of huge trees with the help of pneumatic roots which get adhered to their surfaces, reaching crest that is $10-20$ meters elevated.

\section{Spiritual believes}

It is customarily called money plant and it is speculation leading to prosperity and accomplishment. Contrarily, if expansion or hike of this aroid is diminutive or imbecile, this is an omen of hardship for the incumbent. The leaves simulate coins and thereafter it is denominated to be called as money plant ${ }^{39,40,42}$

\section{Synonyms:}

- Golden pothos

- Pothos aureus
- Scindapsus aureus

- Raphidophora aurea

- hunter's robe

- ivy arum

- money plant

- $\quad$ silver vine

- Solomon Islands ivy.

\section{Common name}

1. English - "centipede tongavine", "devil's ivy", "Golden Ceylon creeper", "Golden pothos", "hunter's robe", "money plant", "pothos", "taro vine".

2. French - "arum grimpant", "liane du diable", "lierre du diable", "pothos doré ", "scindapsus doré"

3. Portuguese-"hera-do-diabo", “jibóia“, "planta-dodinheiro", "trepadeira-de-tonga"

4. Spanish- "ecindapso", "poto", "potos", "potus"

5. German-“Efeutu- te"

Other species of epipremnum ${ }^{4}$

- Epipremnum amplissimum (Schott) Engl

- Epipremnum amplissimum (Schott) Engl

- Epipremnum carolinense Volkens

- Epipremnum ceramense (Engl. and K.Krause) Alderw

- Epipremnum dahlii Engl

- Epipremnum falcifolium Engl.

- Epipremnum giganteum (Roxb.) Schott

- Epipremnum meeboldii K.Krause

- Epipremnum moluccanum Schott

- Epipremnum moszkowskii K.Krause

Uses

Pothos is a preeminent sedentary ornate shoot grown in pendulous bassists, planters and urns let on their stems to plunge down. Although it was generally considered for interior scape purposes but concurrently it is having a compelling aspect of fumigation of its encompassing like, home, work stations, shopping malls and public places For stallions to relieve them of intestinal worms the pneumatic roots of money plant are fed, as well as cut umbrage to crown verdant simultaneously arrangements, decontaminate surroundings from variety of pollutants. $48,49,52,55$ Countryside, Pothos is the most appropriate as a groundcover in garden beds and borders with its sprawling habit, or grown in above-ground planter or small to large containers raised on a pedestal for a cascading effect. Complementing as a climbing vine on trellis, poles, fences, trees or wires. 
This plant is wide used as an element of equatorial land scraping ants as an interior plant rise from pots and hanging from baskets. ${ }^{53,57.58}$ they will treat aldehyde, benzol and $\mathrm{CO}$ (carbon monoxide) from surroundings.

\section{Description}

The regular home ground it has to intensify on trees and backing towers or propagate ponderously over the landscape in dusky areas, extensively cultivated inactive, wherever it upholds in addition delicate behaviour (Nellis, 1997) It belongs to the cultural cluster of climbers, trailers, clinging plants (Singh, 2009) its traditional height is some 10-20 m however is indefinite and dimension entirely depends on coaching.It desires Bright light-weight, halfway choler or refined daylight for best leaf tinge and growth. The regular temperature required for optimum growth is consider hot.Min. $55^{\circ} \mathrm{F}$, moiré often, bright light-weight. desires moderate to ample wet however tolerates drought, need and medium water frequently, permitting the surface to dry out between every wateringWell drained however tolerates standing water typically propagated by Cutting and is of foliage inexperienced with white, yellow or silver markings (sometimes solid yellow or green)these square measure long chains of leaves (depends on training); mature specimens of E.aureum and pinnatum have terribly giant, compound leaves. ${ }^{51,60,62}$

\section{Toxic properties}

The deadly elements haven't been known, however it's suspected that it may contain Raphides and unproven supermolecule toxins and also the primary pain in the ass is metal salt needles.

\section{Symptoms}

The clear, watery sap powerfully irritates the skin and eyes. Internally, it irritates the mouth and throat and will manufacture looseness of the bowels. associate degree allergic dermatitis has been reportable as a results of contact with the leaves. ${ }^{3,10,17}$ There is some doubt whether genus Epipremnum with few ovules on one placenta ought to be united with Rhaphidophora with several ovules on 2 placenta. Bakhuizen Van den Brink projected that they be united. ${ }^{14,15,18}$

\section{Geographcal distribution}

Originally, it absolutely was endemic to the island of Mo'orea from the archipelago. However, it's currently wild in several tropical countries. the subsequent ranges square measure indicated: Bangladesh, Bharat (Andaman Islands), Myanmar, Thailand, Vietnam, People's Republic of China (Hainan, Hong Kong), Taiwan, Japan (Ryukyu Islands, Ogasawara Islands, Bonin Islands), Asian nation (the land, territorial dominion and Sarawak), Singapore, land (Java, Maluku Islands, archipelago, Sulawesi, Sumatra), Philippines, king Islands, Vanuatu, New Caledonia, New Guinea, Australia (Queensland), Marshall
Islands, Hawaii, Palau, Fiji, Tonga, Cook Islands and Western Samoa. ${ }^{47,61,62}$

\section{Cultivation}

In temperate regions it's a preferred flora with varied cultivars hand-picked for leaves with white, yellow, or light-weight inexperienced variegation. it's typically utilized in ornamental displays in searching centers, offices, and alternative public locations mostly as a result of it needs very little care and is additionally beautifully leafed. In tropical countries, it's found in several parks and gardens and tends to grow naturally. As an interior plant it will reach over a pair of $m$ tall if it's given the adequate support (a tutor to climb), however hardly develops adult-sized leaves. the simplest results square measure achieved by providing indirect light; it tolerates associate degree intense brightness, however long periods of direct daylight burn the leaves. It lives well with a temperature between seventeen and thirty ${ }^{\circ} \mathrm{C}$ (63 and eighty-six ${ }^{\circ} \mathrm{F}$ ).

Typically the plant can solely would like watering once the soil feels dry to the bit. A liquid chemical are often extra within the spring and it should be replanted each 2 years. However, it's a really strong plant that supports unhealthy growing conditions. The plant grows apace in aquaculture.

It are often cultivated from a cutting, a locality of a plant utilized in plant propagation. Cuttings but, will carry numerous diseases like Erwinia leaf spot, fungus plant disease, Rhizoctonia foot rot, Pseudomonas leaf spot, Southern blight, and Xanthomonas blight. ${ }^{46,49}$

\section{Morphology}

Golden pothos (Golden pothos) may be a naturally varicolored rise vascular plant that produces copious yellow-marbled foliage. it's among the foremost well-liked tropical decorative plant used as hanging basket crop.An insight has been provided concerning the various sorts of ivy arum as well as element, Marble Queen and Jade Pothos. The flowers of it's alike, Grow pothos inside, ideally with bright, not direct light-weight, though it additionally can tolerate low-light conditions. Pale leaves mean that an excessive amount of sun, and loss of variegation means that insufficient.

Pothos likes to own its soil dry out between watering and thus accepts erratic watering care. It positively dislikes soggy roots. The leaves droop once the plant is thirsty and wishes a drink. however don't let this wilt-y stage opt for too long otherwise you can begin to check leaf drop.33,35,49 Grow in any well-draining potting soil.Pothos may be a light-weight feeder, however you'll provides it a monthly snack with a balanced chemical developed for houseplants.

Plants: Young plants feature bright, waxy, heart formed inexperienced leaves (to 4" long) that square measure varicolored with yellow or white. On giant mature vines, however, the leaves become abundant larger (to 30" long) with deep lobes. E. aureum is associate 
degree evergreen vascular plant growing to $20-\mathrm{m}$ (66 ft) tall, with stems up to four $\mathrm{cm}$ ( 2 in) in diameter.Leaves square measure vibrant and evergreen. they're alternate, heart-shaped, entire on juvenile plants, however on an irregular basis compound on mature plants, up to $100-\mathrm{cm}$ (39 in) long and $45-\mathrm{cm}$ (18 inn) broad [juvenile leaves abundant smaller, usually below $20-\mathrm{cm}$ (8 in) long.Pothos plants don't flower below greenhouse and flowering is rarely recordable even among native habitats. The flowers square measure made during a bract up to $23-\mathrm{cm}$ (9 in) long Stem: This plant is well propagated from stem cuttings. This plant produces trailing stems once it climbs up trees and these stabilise after they reach the bottom and grow on it Roots: In its native home ground, it climbs tree trunks by aerial rootlets and tumbles on the bottom as a ground cowl, reaching up to 40' or additional long. $40,42,46,48$

\section{Flowers}

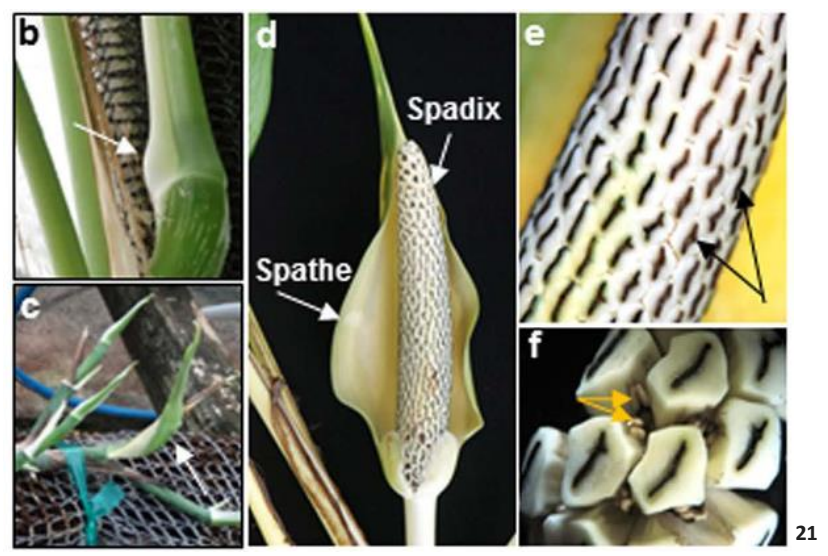

\section{Leaves}

This plant have leaves of variety of colors and patterns easy, glabrous, oblong-lanceolate, sub-entire or on an irregular basis rough, acute or acuminate. They have major varieties like -

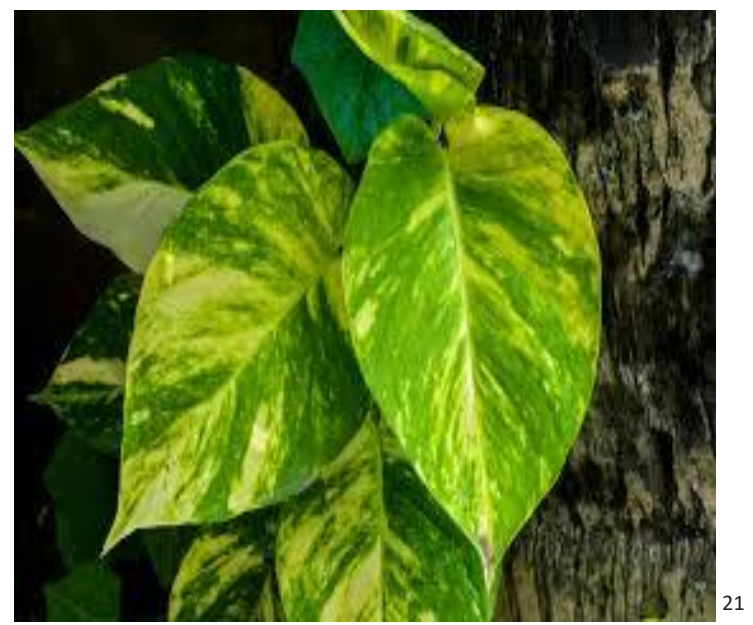

\section{Stems}

The stems are generally green but get turned brown after ageing and act as support systems.

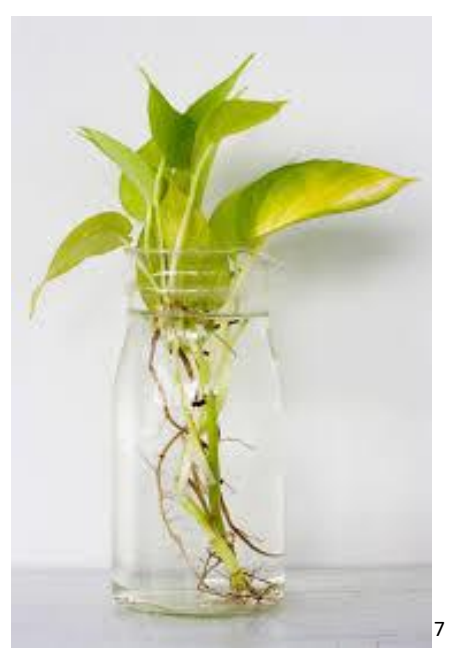

\section{Roots}

Roots area unit typically brown or white in colors however typically area unit accidental. The roots of Epipremnum aureum, doesn't combine phytotoxin themselves however will take up exogenous fed phytotoxin as a xenobiotic as shown in Figure a pair of. The organic compound is afterward translocated to the leaves, via the vascular tissue path, wherever it accumulates within the mesophyll up to levels comparable phytotoxin made genus Nicotiana species. $^{39,56}$

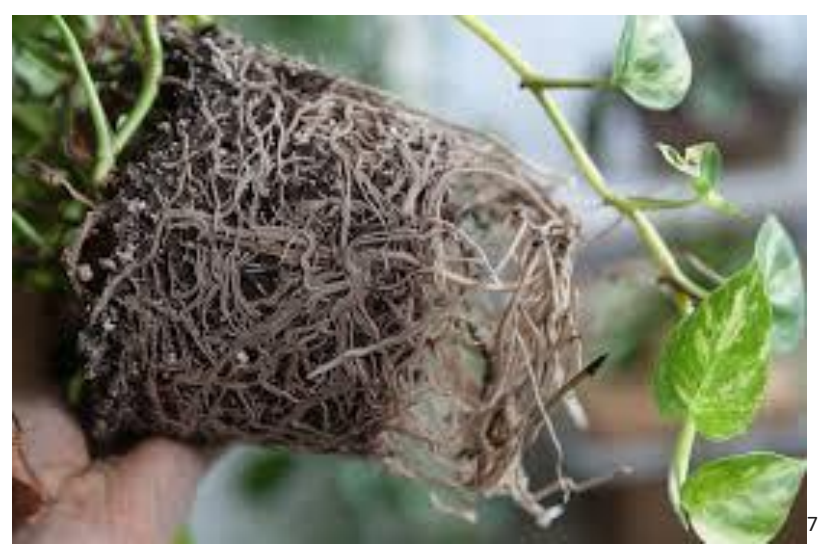

\section{Phytochemical Profile}

Phytochemicals area unit, within the strictest sense of the word, chemicals made by plants. Commonly, the word refers to solely those chemicals which can have a control on health, or on flavor, texture, smell, or color of the plants, however don't seem to be needed by humans as essential nutrients. 5,7,9 Emergence of multi-drug resistance in human and animal unhealthful microorganism likewise as undesirable aspect effects of bond antibiotics has triggered Brobdingnagian interest within the look for new antimicrobial medication of plant origin. $6,10,12$

\section{Different ways of phytoextraction}

Plants area unit an expensive supply of phytochemicals employed in completely different business sectors like food, pharmaceutical and chemical industries. These phytochemicals have to be compelled to be extracted 
from plant materials. therefore there's a desire for the foremost appropriate and customary ways to extract these active parts from plant materials. tho' there area unit varied ways in conjunction with typical ways, until currently there's no single methodology customary for extracting bioactive compounds from plants. The efficiencies of extraction ways depend upon the necessary input parameters; understanding the character of plant matrix; chemistry of bioactive compounds and knowledge base.

The investigation of bond endemic plants for his or her antimicrobial properties could yield helpful results wherever the utilization of plant extracts and phytochemicals are often of nice significance in therapeutic treatments. within the previous couple of years, variety of studies are conducted in numerous countries to prove such potency ${ }^{7,8}$. The phytochemical screening of various solvent extracts of the aerial roots of Pothos aurea (Rhaphidophora aurea) that climbed on betel palm (betel nut palm) allotted by customary procedures reveal the presence of phytochemical constituents like alkaloids, flavonoids and anthraquinone. The uptake rates of low-molecular weight aldehydes and ketones by pothos (Epipremnum aureum) leaves at typical indoor close concentrations (101"102 ppbv) were reportable. The living thing concentration to the external (ambient) concentration (Ci/Ca) was considerably lower for many aldehydes than for many ketones 12,11 tannins and glycosides 10, 11 phenols 8 steroids, and carbohydrates in its extracts. completely different solvent extracts of aerial roots of Pothos aurea (Rhaphidophora aurea) that climbed on Lawsonia inermis (Mehandhi) showed constituents like alkaloids, flavonoids, tannins, glycosides and anthraquinone..$^{45,46,48}$

Ethyl acetate extract of aerial roots of Raphidophora aurea was most in supersonic homogenization. Phytochemical screening of the extract showed alkaloids, flavonoid, etc. and extracts showed a decent antifungal activity against Aspergillus flavus and Candida albicans.13,25 The ester extracts of the aerial roots of Raphidophora aurea that climbed on betel palm showed sensible medicinal drug and antifungal activity against E. coli, staph aureus, Candida albicans and Aspergillus flavus. The presence of biologically necessary constituents in aerial roots of Rhaphidophora aurea is kind of obvious. ${ }^{9,14,17}$

The medicinal drug, antitermites and inhibitor properties of root and leaf explants extracts of Epipremnum aureum (Araceae). Showed vital repressing activity of fermentation alcohol extract of each leaf and root followed by fuel and solvent extracts. Water extracts of aerial root have stifled the expansion of organism with inhibition zone admire customary (Streptomycin). The crude extracts of various elements (leaves and aerial roots) of E. aureum have additionally been used as AN antitermite's and inhibitor activity (enzyme CAT, SOD and PX) that has industrial application. The positive results counsel that Epipremnum aureum extracts shows to see the bioactive chemical compounds likewise on perceive the attainable mechanism of action and measure their toxicity trying towards pharmaceutical actions.

The fuel extract of pothos exhibited vital broad spectrum antimicrobial activity against Staph aureus, Escherichia coli and yeast organism Saccharomyces cerevisiae at a degree of two decimal five $(2.5) \mathrm{mg} / \mathrm{ml}^{33,37}$

\section{Phytoconstituents}

Phytochemicals are not needed by humans as essential nutrients, have a control on health or on flavour, texture, smell or color of the plants. Phytochemical screening is wide allotted for all plants to throw lightweight on the varied metabolites gift in them. This review of literature is restricted to phytochemical screening of plants of Rhaphidophora genus. The phytochemical screening results of methanolic leaf extract of Epipremnum aureum disclosed the presence of reducing sugar, proteins, tannins, phenols, alkaloids, glycosides and flavonoid. Preliminary phytochemical screening of Scindapsus officinalis fruit solvent extracts disclosed the presence of flavonoids, phenolics, alkaloids, saponins, tannins, glycosides, terpenoids, steroids and fat and oils (hexane extract). completely different chemical compounds like alkaloids, catachin, coumarins, tannins, saponins, flavonoids, phenols, sugars, glycosides and xanthoprotein area unit detected in leaves of Pothos scandens. These tests hint on the utility of the plant in drugs and scope of being a resource for medication. Phytochemical screening of stem crude oil ether and fermentation alcohol extracts of Rhaphidophora pertusa disclosed the presence of alkaloids, glycosides, carbohydrates, flavonoids, phenols, saponins and tannins. Methanolic extract of Epipremnum aureum disclosed presence of alkaloids, flavonoids, tannins, terpenoids, anthraquinones and alkaloids, flavonoids, tannins, glycosides, anthraquinones, sterols, phenols in liquid extract of plant HPLC analysis of the fermentation alcohol extracts of the leaf and root of Epipremnum aureum has disclosed the presence of quercetin dehydrate, ferulic acid, cinnamic acid, caffeic acid, sinnapic acid, p-coumaric acid and phytoconstituents like tannins, viscus glycosides, endocrine terpenoids, saponins, saponins glycosides, anthraquinone, flavonoids, phenols and alkaloids.

A very low rate of adsorption of aldehydes and ketones onto the leaf surface has been reported for two houseplants namely Spathiphyllum clevelandii and Epipremnum aureum. Saponin, an important member of natural products is reported to be in the leaf extract of Pothos scandens. Steroidal saponins such as cardiac glycosides show to be confined to many families and have immense pharmaceutical importance because of their relationship to sex hormones, diuretic steroids, cortisone, vitamin D etc.

\section{Metabolites from Rhaphidophora genus}

Bioactive compounds in plants are secondary plant constituents eliciting pharmacological or toxicological 
effects have important functions in the living plants such as protection, attraction, signaling etc. Present work on isolation of metabolites ${ }^{44}$ from the genus Rhaphidophora/Pothos/Epipremnum is presented here. The 95\% aqueous ethanolic extract of Rhaphidophora hongkongensis, yielded ten compounds - lupeol and its acetate, sitosterol, betulinic acid, betulinol, stearic acid, ficubee $A$, ficubee $B$, artelastin and $\beta$-daucosterol. Nine flavonoid glycosides vitexin, vitexin 7-O-glucoside, isovitexin 7-O-glucoside, isoscoparin 7-O-glucoside, scoparin 7-Oglucoside, schaftoside, isoschaftoside and chrysoeriol 7-0-rhamnosylglucoside and 7-Odiglucoside were isolated from the aerial parts of Pothos chinensis. R.korthalsii and compounds isolated from the extracts of this plant namely lectin and zerumbone are potent immunostimulators. Presence of 23 volatile constituents is reported in Scindapsus aureum and Hedera nepalensis through GC-MS analysis of the 11 terpene compounds, $\alpha$ pinene and camphene are reported as major terpene compounds in both the plants. Without entering mesophyll nicotine is absorbed onto the leaf surface and also taken up by roots as seen from the study on the detoxification potential for air pollutants by Epipremnum aureum. Nicotine and cotinine in the leaves of Epipremnum aureum, extracted with $0.5 \%$ sodium hydroxide and ethanol under ultrasonic for $30 \mathrm{~min}$ has been detected by UPLC method. The alkaloid is subsequently trans located to the leaves, via the xylem path, where it accumulates in the mesophyll up to levels comparable with nicotine - rich nicotiana. Bioassaydirected fractionation led to the isolation of 14 compounds namely polysyphorin, grandisin, pigrandisin, (+)medioresinol, (-)-pinoresinol, (-)-syringaresinol, (+)glaberide I, (-)-liliolide, (+)-dehydrovomifoliol, (-)hydroxydihydrobovolide and $\mathrm{N}$-butylbenzamide from Rhaphidophora decursiva. Six of the isolated compounds showed appreciable antimicrobial activity. Rhaphidecursinol $A$ and rhaphidecursinol B were determined to be new neolignans and rhaphidecurperoxin a new benzoperoxide. ${ }^{56}$

Antimalarial bioassay-directed fractionation led to the isolation of a novel active indole alkaloid, decursivine, from the stems and leaves of Rhaphidophora decursiva. In addition, a leaf sample yielded the structurally-related compound serotobenine. 5, 6-dihydroxyindole was isolated from fresh leaves of R.korthalsii. The constituents like, benzonid (11-phenyldecanoic acid, 15phenylpentadecanoic acid, 13- phenyltridecanoic acid, alkaloid (tongine) have been isolated from Epipremnum pinnatum. ${ }^{23}$

\section{Anti-inflammatory constituents}

Inflammation is a part of the complex biological response of vascular tissues to harmful stimuli. Redness, swollen joints, joint pain, stiffness and loss of joint function are some of the indications. NSAIDs commonly used to treat inflammation can cause heart attack and stroke. Hence there is a need for anti-inflammatory drugs from natural products which house hundreds of phytoconstituents. This portion of review is directed towards compilation of data of plants extracts against inflammatory models. ${ }^{22,25}$

The $P$. scandens inhibits mast cell-derived allergic reactions and is a potential allergic anti-asthmatic agent. The fruit ethanolic extract of Scindapsus officinalis produces significant anti-inflammatory and analgesic activity.

The ethanolic fruit extract of Scindapsus officinalis possesses anti-inflammatory and analgesic activities. The inhibitory effect of ethanol extract of Rhaphidophora pertusa and Epipremnum pinnatum on carrageenan induced inflammation in rats is reported to be due to the inhibition of the enzyme cyclooxgenase, leading to inhibition of prostaglandin synthesis. Rhaphidophora pertusa is used as an anti-inflammatory and antidote agent in the traditional medicine of Kerala. ${ }^{52,58,59}$

\section{Bacterial isolation}

Ralstonia solanacearum ${ }^{20}$ was isolated from diseased Pothos (Epipremnum aureum) cutting imported to Florida from Costa rica. Epipremnum aureum has not previously been described as a hot of R. solanacearum 19. Agro bacterium tumefaciens-mediated transformation of Golden pothos (Epipremnum aureum) plants, the effects of selection antibiotics and the preculture period of stem explants before A. infection of tumefaciens were examined. Reproducible transformation system for Golden pothos may enable the molecular breeding of this very common indoor plant. ${ }^{21}$ The bacterial leaf spots of foliage plants were caused by Pseudomonas cichorii organism. Its susceptible plants are Epipremnum aureum (Pothos), the symptoms varied and may include brownish-black lesions, light and dark zones on Epipremnum aureum leaves. ${ }^{22}$

\section{Isolation of viruses}

Pothos latent virus (PoLV) was isolated by inoculation of isolated sap from symptomless plants of Scindapsus aureus (Pothos, family Araceae) growing in hydroponic culture. A virus, for which the name of PoLV is proposed, was isolated by inoculation of sap from symptomless plants of Scindapsus aureus. The biological properties of PoLV resembled those of Tombusviridae for it infected most of the artificial hosts locally, inducing symptoms recalling those elicited by several species of the above family. ${ }^{23}$

The complete genomic sequence of Pothos latent virus (similar to that of tombusviruses) has been determined. The results support the conclusion that PoLV is a new but atypical member of the family Tombusviridae. ${ }^{24}$ Pothos latent virus is an isometric virus with a positive-sense, single-stranded RNA genome of 4415 NT. The genome contains five open reading frames (ORF), coding for five proteins. In vitro synthesized PoLV RNA was infectious to Nicotiana benthamiana plants and protoplasts, but could not support replication of the defective interfering (DI) and satellite RNAs associated with cymbidium rings pot 
tombusvirus. No D RNA related to PoLV was generated after repeated passaging with infected sap. ${ }^{28}$

The cytopathology of infections by the initial isolate of Pothos latent virus (PoLV-WT), associate degree unclassified tombus-like virus, associate degree infectious in vitro transcript of its ribonucleic acid (PoLV-IF), and 2 ribonucleic acid transcripts secret writing for noneucapsidationcompetent coat proteins (PoLVBstB and PoLV-Nhe) was relatively studied in genus Nicotiana benthamiana. ${ }^{26}$

\section{Nicotine uptake}

Investigation of the detoxification potential for air pollutants by liana unconcealed absorption of vasoconstrictive onto the leaf surface while not getting into mesophyll. it's concerned by the roots of E. aureum. The vasoconstrictive and cotinine within the leaves of liana was extracted with the admixture of zero.5\% hydroxide and grain alcohol below inaudible for 30 min. vasoconstrictive and cotinine were detected within the plants by UPLC technique. The results indicated that plants can be injured in expression labelled sequences (ETS), and vasoconstrictive could be metabolized by plants ${ }^{29}$. The roots of liana tho' not synthesizing vasoconstrictive themselves, take up exogenously fed vasoconstrictive as a xenobiotic. The organic compound is afterwards translocated to the leaves, via the vascular tissue path, wherever it accumulates in the mesophyll up to levels comparable vasoconstrictive - wealthy genus Nicotiana species. ${ }^{30}$

\section{Pharmacological Activities}

\section{Phytoremediation}

Phytoremediation could be a novel technology for treatment of low and intermediate level fluid hot wastes originated from the daily use of nuclear technologies in life. Studies have shown that Epipremnum will accumulate Co sixty and metallic element 137 from solutions, each within the presence additionally as absence of stable carriers and nutrient ions while not apparent toxicity. Thus, for solutions within which typical cleanup is unsuitable or valuable, Epipremnum would possibly supply a way of Co sixty and metallic element 137 accumulation. ${ }^{11,17}$

\section{As Antimicrobial Agent}

The plant exhibits broad spectrum antimicrobial activity against numerous pathogens. Leaves and aerial roots of the $E$. aureum have shown nice potential of antimicrobial. Some of the plant extracts possess compounds with antimicrobial properties that may be any explored for antimicrobial activity. The ethanolic leaf extract of $E$. aureum is effective against E.coli, bacteria genus luteus, grass bacillus, B.cereus whereas the binary compound extract of roots of E. aureum area unit effective against E. coli and bacteria genus luteus. The methanolic root extract is effective against grass bacillus, and therefore the root extract with resolvent is effective against B.cereus. ${ }^{20}$

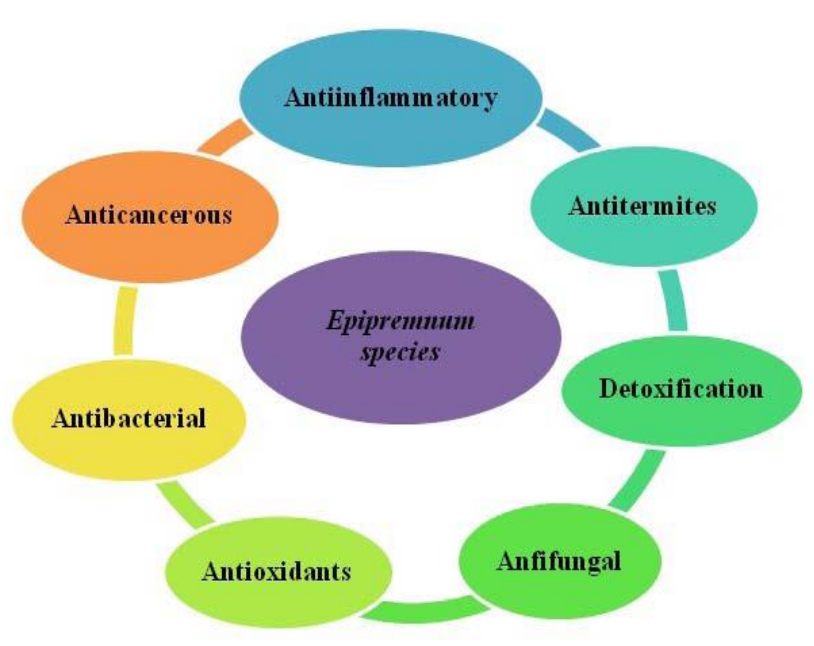

Figure 3: Ethnomedicinal and pharmacologic properties of Epipremnum species ${ }^{54}$

\section{Anti-bacterial and Anti-fungal}

Various solvent extracts of $E$. aureum leaves and aerial roots unconcealed medicament activity against microorganisms, it's been found that water extracts of aerial root half showed clear and roughly similar zone of inhibition compared to straightforward disc against check organisms in decreasing order enterics coli>Micrococcus luteus>Bacillus cereus>B. subtilis. ${ }^{18,48,56}$. Methanolic leaf extracts of $E$. aureum showed medicament activity against Escherichia and cocci aureus and therefore the antifungal activity was evaluated against candida. ${ }^{23}$ The ethyl group extract of the aerial roots of Raphidophora aurea (climbed on feather palm catechu) conjointly showed against medicament and antifungal activity. ${ }^{19,}{ }^{24}$ Fossil oil ether, resolvent and grain alcohol extract of $E$. aureum shows right smart medicament activity against $E$. coli and $S$. aureus. ${ }^{18}$

\section{Antioxidant activity}

The main characteristic of associate degree inhibitor is its ability to lure free radicals. extremely reactive free radicals and atomic number 8 species area unit gift in biological systems from a large sort of sources. ${ }^{27}$ Ester fraction of extract from ivy arum has potential repressive activity against alphaglucosidase and inhibitor effects, and nbutanol fraction has nice antioxidative effects. ${ }^{28}$ inhibitor activity testing of various solvent extracts of the aerial roots of Pothos aurea tangled over on Lawsonia inermis and betel palm dole out by one, 1-diphenyl-2-picryl hydrazyl (DPPH) radical scavenging assay and reducing power check show higher inhibitor potential of the extracts. The considerable atom scavenging activity of the extracts can be thanks to the secondary metabolites alkaloids, flavonoids, tannins, phenols and anthroquinones gift within the extracts. The plants could also be thoughtabout nearly as good sources of natural antioxidants for healthful uses like against aging and alternative diseases 
associated with radical mechanisms ${ }^{28,29}$ easy and effective regeneration ways were established for propagating Epipremnum aureum 'Golden pothos', genus Syngonium podophyllum 'Variegatum', and genus Lonicera macranthodes 'Jincuilei', 3 vital healthful plants. corporal embryos shaped directly at the cut edges or on the surface of stalk explants of Epipremnum genteel on MS medium supplemented with TDZ (N-phenyl-N'-1,2,3-thiadiazol-5ylurea) and NAA (a-naphthalene carboxylic acid acid) or TDZ and a pair of,4-D (2,4-dichlorophenoxyacetic acid). All regenerated plantlets grew smartly when transplantation to a soilless instrumentality substrate in a very shaded greenhouse 30,37,39 Epipremnum pinnatum (L.) Engl. chloroform extract created important growth inhibition against T-47D breast cancer cells and analysis of death mechanisms indicated that the extract evoked each apoptotic and nonapoptotic programmed cell deaths . $^{46,49}$

\section{Calming result}

It was found that actively touching a leaf of natural pothos caused individuals to expertise associate degree unconscious calming response. This analysis supports the varied previous studies that plants, nature and material of natural origin bring feelings of relaxation to individuals. The results of this experiment might need been totally different |completely different\} if leaves with numerous different surface varieties had been used and it's necessary to look at this any. This report offers a brand new framework for understanding the connection between individuals and plants or nature.12

\section{Role in fengshui and vastu shastra}

There is a preferred belief if honesty thrives well it brings prosperity. Hence, the great growth of liana in associate degree household is an indicator of wealth. Growing nature of the plant shows that cash plant could be a perennial climber and young plants bear three-four inches long cordate leaves. honesty is taken into account an honest principle plant because it is taken into account to get rid of toxins from the air caused by improvement product and trendy furnishings product of artificial materials. It energizes the house by filtering air and increasing atomic number 8 flow. principle consultants suggest keeping one plant close to every pc, tv or LAN router. inserting honesty before of a pointy corner or angle reduces anxiety and stress. Vaastu specialists suggest planting of cash plant within the house because it brings smart luck to the house. additionally to basic chemical action that removes dioxide and returns $\mathrm{O}$ to the air, plants will take away toxicants from air, soil, and water as they will metabolize some harmful chemicals, cathartic harmless by-products, and additionally they will incorporate toxicants like significant metals into plant tissues, therefore sequestering them. ${ }^{56,59,60}$

\section{Detoxification}

Golden Pothos has been the plant in removing methanol. it's been found effective in removing benzol and $\mathrm{CO}$ too. The detoxification potential of air pollutants by liana exposed, absorption of phytotoxin onto the leaf surface while not getting into mesophyll. it's concerned by the roots of E. aureum ${ }^{27}$. The roots of liana tho' not synthesizing phytotoxin themselves, take up exogenous fed phytotoxin as a xenobiotic 28. Thus E. aureum has detoxification potential for methanol and phytotoxin and might be used for self-regenerating bio-filter system for indoor air purification. ${ }^{26}$ According to the NASA/ALCA study on the employment of common indoor plants for indoor air purification Scindapsus aureus is one in every of the highest 3 plants besides liana and Cleome hassleriana that has been labeled the foremost effective in removing methanal. Scindapsus aureus big on Associate in Nursing activated charcoal filter system reduced air levels of benzol and ethylene within a Plexiglas chamber mensuration zero. ${ }^{61}$ Capacity measure from roughly thirty six ppm to barely detectable levels inside a pair of hours. One indoor stuff of explicit concern is methanol, that is free by several unit merchandise, among them ironed woods, some sorts of foam insulation, paper merchandise, some paints and varnishes, and drip-dry materials. The National pharmacological medicine Program lists methanol as fairly anticipated to be a person's matter. Those studies work well with proof on the organic chemistry mechanisms concerned in plant detoxification of methanol. 3 varieties of potted plants were tested for his or her capability to get rid of methanol from indoor air. it absolutely was found that the formaldehyde-removal capability of the plants trusted the dehydrogenase activity within the leaves and root system-that is, however with efficiency the plant might metabolism methanol. ${ }^{6}$ It absolutely was additionally found that plants take away methanol through diffusion-limited as earlier according. Formaldehyde may be a major indoor air waste. Its removal from air will cut back the health risk of urban population. liana is incredibly effective plant is removing methanol. it's greatly appropriate for garage since automobile vehicle exhaust contains methanol. it's the aptitude to soak up and metabolize methanol that may be a major indoor waste. Study has been conducted on the removal of benzol by liana ${ }^{21}$ These plants may also cut back benzol and ethylene levels. 22

\section{Antitermites Activity}

Studies show five0|that fifty concentration of aerial root extract in grain alcohol shows antitermites activity in 5 minutes from ninety six to $100 \%$ whereas liana root extract in water

has shown antitermites activity when ten minutes. Thus, this plant may be cheaply controlled in combating agricultural infections and might be used for pestered management ${ }^{15}$ it's been initial according that every one elements of this plant ideally root extract in grain alcohol was stiffer, ninety six to hundred \% against termites and considerably totally different from the \% mortality up to the mark (crude ethanol) that's sixty share ${ }^{20}$. Studies are conducted to point out the in vitro antitermite impact thanks to alkaloids isolated from $E$. 
aureum against Indian White insect Odontotermes obesu s. Highest fatality rate is according in alkaloids isolated from leaves compared to stem and roots. Therefore, supporting the employment of this plant for the event of seasoner formulations to beat artificial termiticides borne issues. . $^{25,33,46}$

Similarly in HPLC studies phenolic resin acids detected within the alcoholic extracts of the material by chromatograms. variety of peaks were detected, a number of that might be known within the presence of rare standards. In the E. aureum plant, cinnamic acid and quercetin dehydrates square measure ordinarily gift in each explants (leaf and root) whereas Caffeic acid, sinnapic acid and p-coumeric acid square measure known solely in root explants. ${ }^{20,22,40}$

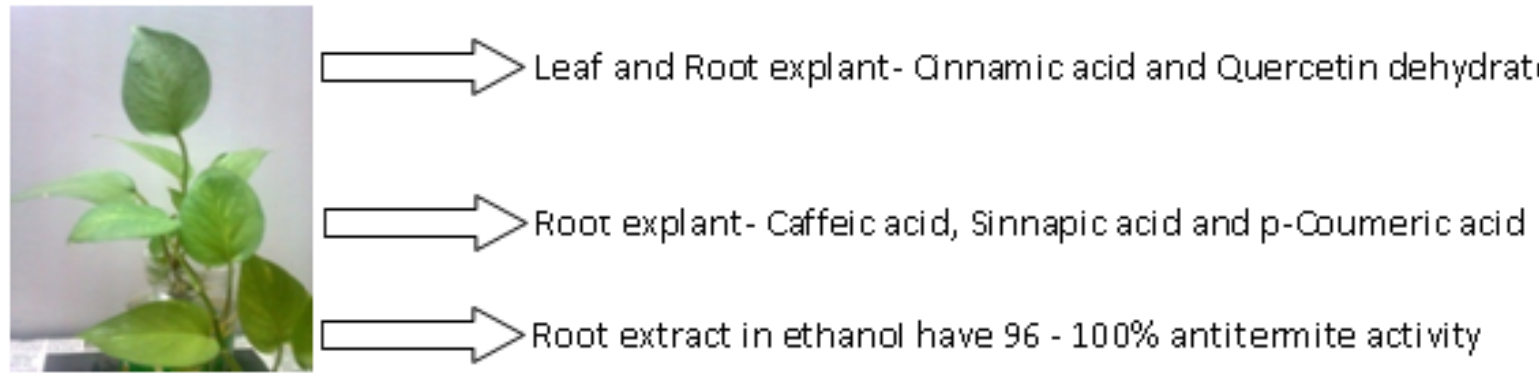

Epipremnum aureum

Phenolic acid determination in HPLC

Figure 4: phenolic resin acid determination in liana by HPLC 20

\section{Locomotor activity in rats}

it acts as CNS depressant and its move activity is tested in male swiss unusual person rats advisement 150-200 g with dose of two hundred $\mathrm{mg} / \mathrm{kg}$ of epipremnun extract, there's important reduction in actophotometer reading within the check cluster animals as compared to the standards and this was thanks to the CNS depression. ${ }^{40,43}$

\section{Anti-cancer}

Chloroform extracts of monocot genus pinnatum (L.) Engl. Showed important growth inhibition against T-47D breast malignant neoplastic disease cells and more death mechanisms indicated that the extract induced each apoptotic and non-apoptotic programmed cell deaths. ${ }^{23}$

\section{Anti-oxidation}

Antioxidant activity testing of various solvent extracts of the aerial roots of Pothos aurea tangled over on Lawsonia inermis and Areca catechu dole out by one, 1- diphenyl-2-picryl hydrazyl (DPPH) radical scavenging assay and reducing power check show higher inhibitor potential of the extracts ${ }^{24,27}$. The crude extracts of liana each (leaves and aerial roots) have additionally been used for its antioxidative properties. oxidase (PX) enzyme (SOD) and Catalyse (CAT) activity of the plant's leaf extracts showed positive results that have industrial application and looking out forward pharmaceutical actions. $^{20}$

Effect of E. aureum extracts on anti-diabetic activity in alloxan-induced diabetic rats ${ }^{19}$

The animals treated with two hundred $\mathrm{mg} / \mathrm{kg}$ of AQEEa and ALEEa shown a big decrease $(p<0.01)$ in FBGL on seventh, 14th, and twenty first day of treatment in comparison to alternative teams of animals. The binary compound extract has reduced additional (\%) in FBGL in comparison to alcoholic extracts except commonplace cluster. The elaborate results square measure summarized in Table one

Table 1: Effect of extracts of E.aureum on fasting blood glucose level (FBGL) in alloxan-induced diabetic rats ${ }^{19}$

\begin{tabular}{|c|c|c|c|c|c|}
\hline Treatment & Dose $\mathbf{( m g / k g )}$ & Blood glucose level $\mathbf{( m g / k g}$ ) day & 7th day & $\mathbf{1 4 t h}$ day & 21st day \\
\hline Normal control & - & $100 \pm 1$ & $100 \pm 1$ & $96 \pm 1$ & $97 \pm 2$ \\
\hline Diabetic control & 10 & $253 \pm 2$ & $256 \pm 3$ & $264 \pm 2$ & $271 \pm 1$ \\
\hline Glibenclamide & 10 & $98 \pm 1$ & $96 \pm 3$ & $80 \pm 1$ & $72 \pm 2$ \\
\hline AQEEa & 200 & $117 \pm 2$ & $104 \pm 1$ & $89 \pm 2$ & $76 \pm 1$ \\
\hline ALEEa & 200 & $103 \pm 2$ & $98 \pm 2$ & $86 \pm 2$ & $77 \pm 1$ \\
\hline
\end{tabular}

Both the AQEEa and ALEEa (200 mg/kg) considerably $(p<0.01)$ suppress the increase in FBGL once aldohexose load $(2 \mathrm{~g} / \mathrm{kg})$ in rats, initially $1 / 2$ time unit and up to a pair of hrs amount as compared with different teams extract glibenclamide on fifteenth day, whereas AQEEa and ALEEa created vital reduction in FBGL. Glibenclamide $(10 \mathrm{mg} / \mathrm{kg})$ showed $(p<0.01)$ vital suppression in FBGL rise initially $1 / 2$ time unit, $1 \mathrm{hr}$, and normalized FBGL inside a pair of hrs. 
leaves of E. aureum have shown the good potential of antidiabetic activity in traditional and alloxan-induced rats. Awareness of local people ought to be increased incorporating the standard data with scientific medicine. The medical specialty activities of this studies support the folkloric usage of plant and counsel that E. aureum extracts may additionally possess antipsychotic, hypolipidemia, anti-convulsants, etc., may be studied additional. ${ }^{47,57}$

Based on the phytochemical screening, it's been closing that each the binary compound and alcoholic extracts had symptom activity as a result of the presence of flavonoids, that are wealthy within the treatment of symptom with fewer facet effects. Flavonoids can be manufacturing symptom impact by a mechanism freelance from hormone secretion, e.g. by the inhibition of endogenous aldohexose production or by the inhibition of enteric aldohexose absorption. This study E. aureum of each binary compound and alcoholic extracts was showed vital impact on aldohexose tolerance and conjointly showed reduction in FBGLs in traditional diabetic rats.

\section{Toxicity}

Plant ingestions are among the chief reason behind accidental poisonings in youngsters younger than five years. Pets are common victims of plant poisonings ${ }^{8}$. The plant is listed as "toxic to cats and unhealthful to dogs" by the ASPCA because of the presence of insoluble metal oxalates. Ca-oxalate could be a substance that forms needle-shaped crystals. Its statement is $\mathrm{CaC} 2 \mathrm{O} 4$ or Ca2. metal salt crystals or being concerned in defense against termites, chick pea and different pests. Therefore, it's used as effective natural pesticides, it conjointly concerned in metal regulation. All elements of this plant ar toxic with unhealthful metal salt crystals. Care ought to be taken to confirm that plant isn't consumed by house pets. Symptoms might embody oral irritation, vomiting, eye pain, skin irritation, mouth swelling etc. ${ }^{24}$

\section{REFERENCES}

1. Srivasatava.N, Shwarupa.S, Bhagyawant S.S., Comparative Study on the Anti-Termite, Antimicrobial and Antioxidant Activity of Leaf and Root Extracts of Pothos aurea (Epipremnum aureum L.), Journal of Pharmaceutical Research \& Clinical Practice, Apr-June 2011; 1(2): 1-11.

2. Poole RT, Chase AR, Osborne LS, CFREC-A Foliage Plant Research Note RH- 1991-29, journal of Institute of Food and Agricultural Sciences, Central Florida Research and Education Center, Apopka; 2018; 5: 44-49.

3. Liliwirianis N, Wan Z, Wan M Z, Kamaruzaman J, Screening of Epipremnum Sp., Syngramma alysmifolia, Thotea Sp. and Smilax Sp. For Antimicrobial Activity; journal of World Applied Sciences, 2010; 8 (7): 889-891.

4. Meshram A, Srivastava N. Molecular and physiological role of Epipremnum aureum. International Journal of Green Pharmacy 2014; 8: 73-76.

5. Bakhuizen VD, Brink RC, Are Epipremnum Schott, Raphidophora Hassk., and Monstera Adanson congeneric
Blumea Supplement, International Journal of Green Pharmacy, 1958; 4: 91-92.

6. Jed W F, Moringa SCD, A Review of the medical evidence for its nutritional, therapeutic, and prophylactic properties, Trees for life Journal, Part 1: 42-54

7. Ahmad I, Beg AZ, Antimicrobial and phytochemical studies on 45 Indian medicinal plants against multi-drug resistant human pathogens, Journal of Ethnopharmacology, 2001; 74: 113-123.

8. Ikram $M$, Inamul $H$, Screening of medicinal plants for antimicrobial activities, Journal of Pharmaceutical Research \& Clinical Practice,1984; 10: 62-64.

9. Cowan MM, Plant products as antimicrobial agents, journal of Clinical Microbiological Review, 1999; 12: 564582.

10. Parulpriya $\mathrm{P}$, Lalitha $\mathrm{P}$, Phytochemical constituents and antimicrobial activity of the aerial roots of Rhaphidophora aurea twined over Areca catechu, National conference on natural product research: for health and biopharma industry, 2011; 12: 24

11. Arathi KA, Lalitha $P$, Jayanthi $P$, Shubashini $K \mathrm{~S}$, Phytochemical investigation of the Aerial roots of Pothos aurea (Linden ex Andre), report of 3rd Indo- Korean joint seminar on medicinal plant research, 2010: 53.

12. Lalitha $P$, Arathi KA, Shubashini K S, Hemalatha S, Jayanthi $P$, Antimicrobial activity and Phytochemical screening on an ornamental foliage plant Pothos aurea, Asian journal of Pharmaceutical and clinical research, 2010; 1(2): 1-07.

13. Tani.A, Nicholas H C, Uptake of aldehydes and ketones at typical indoor concentrations by houseplants, journal of Environmental Science and Technology, 2009; 43 (21): 8338-8343.

14. Parulpriya $P$, Lalitha $P$, Efficiency of different solvent extraction methods in the isolation of bioactive principles from the ethyl acetate extract of Rhaphidophora aurea, International conference in "Global competitiveness in biology, chemistry and environment for a better tomorrow, 2011; 10: 48

15. Meshram A, Srivastava N. "epipremnum aureum (jade pothos): a multipurpose plant with its medicinal and pharmacological properties" Journal of Critical Review; vol 2 (issue 2); 2015: 45-46.

16. Abhigyani $G$,Naga K R, Fathima B, Agarwal P, Anti diabetic activity of Epipremnum aureum in normal and alloxan induced diabetic Rats ; Asian journal of Pharmaceutical and clinical research ; Vol.9; ;issue 4; 2016: 54-57.

17. Srivastava N, Shwarupa S, Bhagyawant SS, Comparative study on the anti-termite, antimicrobial and antioxidant activity of leaf and root extracts of Pothos aurea (Epipremnum aureum L.),Journal of Pharmaceutical Research and Clinical Practice 2011; 1: 111.

18. Yang $\mathrm{H}$, Liu Y. Phytoremediation on air pollution In: The impact of air pollution on health, economy, environment and agricultural, international journal of environmental technology ; 2011; Vol 1: 281-94.

19. Douglass F. Indoor air quality-planting healthier indoor air, News forum Environmental Health Perspectives, 2011; 119: A426-427. 
20. Lan TM, Sulaiman SF, Najimudin N, Muhammad TST, Anticancer medicinal plant Epipremnum pinnatum chloroform extracts elicited both apoptotic and nonapoptotic cell deaths in T-47D mammary carcinoma cells, KMITL Science and Technology Journal 2007; 7: 24-43.

21. Palmer M, Betz JM. Plants. In: Goldfrank LR, Flomenbaum NE, Hoffman RS, Howland MA, Lewin NA, Nelson L. editors. Goldfrank Toxicologic Emergencies. 8; 2006: 1577-602.

22. Meshram A, Srivastava N. In vitro antitermite activity of alkaloids from Epipremnum aureum (Linden and Andre) Bunting (Araceae) against Indian White termite Odontotermes obesus. Asian Journal of Pharmaceutical Technology and Innovation, 2015; 3(10): 27-31 .

23. Weidner M, Silva JAT, Potential and limitations of ornamental plants for indoor air purification, Journal of Floriculture, ornamental and plant biotechnology, Advances and Topical Issues, 2006; 4: 54-63.

24. Liu ZC, Lu SM, Liu CB, Zhao YF, Wang HL, Li JM, et al. Simultaneous determination of nicotine and cotinine in leaves of plants in ETS by UPLC, the journal of Chemical Engineering 2008; 12: 43-45.

25. Weidner M, Martins R, Muller A, Simon J, Schmitz H. Uptake, transport and accumulation of nicotine by the Golden pothos (Epipremnum aureum): the central role of root pressure. J Plant Physiology 2005; 162: 139-50.

26. Zheng-cong IU, She-ming LU, Chun-bo LIU, Yun-fang ZHAO, Hai-li WANG, Jinming LI, Ming-ming MIAO, Simultaneous determination of nicotine and cotinine in leaves of plants in ETS by UPLC, Chemical engineer, 2008; 12: 33.

27. Manfred Weidner, Ralf Martins, Andrea Muller, Judith Simon, Heribert Schmitz Uptake, transport and accumulation of nicotine by the Golden potho (Epipremnum aureum): the central role of root pressure, Journal of plant physiology, 2019; 162: 139-150.

28. Normon DJ, Yuen JMF, A distinct pathotype of Ralstonia (Pseudomonas) solanacearum race 1 , biovar 1 entering Florida in Pothos (Epipremnum aureum) cuttings, Canadian journal of plant pathology, 2015; 20: 171-175.

29. Heather L Papinchak, Jay Holcomb E, Teodora Orendovici Best, Dennis R Decoteau, Effectiveness of houseplants in reducing the indoor air pollutant ozone, journal of Horticulture Technology, 2009; 19(2): 286-290.

30. Yuichi T, Matsuzaki T, Yuya $T$, Isolation and characterization of formaldehyde-responsive genes from Golden pothos (Epipremnum aureum), journal of Plant biotechnology, 2010; 27: 325-331.

31. Kil MJ, Kim KJ, Kim HH, Lim YW, Effects of growing media and exposure frequency on the volatile formaldehyde removal in potted Epipremnum aureum, Korean journal of Horticultural Science and Technology, 2008; 26(3): 325330.

32. Jeong SJ, Kim WS, Lee DW, Kim HD, Kim KJ, Yoo EH, Cho JG, Evaluation of selected foliage plants for improvement of indoor humidity, horticulture, environment, and biotechnology, Korean journal of Horticultural Science and Technology, 2008; 49(6): 439-446.

33. Park J.S, Masahisa Ishii, Limi O, Sadanori S, Kazuhiro Fujiwara,Effects of ozonated water-fog cooling on ozone gas concentrations and population densities of airborne bacteria and fungi on plant leaves in a naturally ventilated greenhouse, The Japan Agricultural Research Quarterly, 2008; 42 (4): 291 - 297.

34. Tarran J, Torpy F, Burchett M, Use of living pot-plants to clean indoor air - research review, Proceedings of sixth international conference on indoor air quality, Ventilation \& energy conservation in buildings - Sustainable built environment, 2007; Volume III: 249-256.

35. Orlikowski LB, Trzewik A, Wiejacha K, Phytophthora tropicalis on Hederahelix and Epipremnum aureumin Polish greenhouses, Journal of Communicative Agriculture and Applied Biology, 2019; 5: 56-67.

36. Lalitha P, Arathi KA, Sripathi SK, Hemalatha S, Jayanthi P. Antimicrobial activity and phyto chemical screening of an ornamental foliage plant, Pothos aurea (Linden ex Andre). Alfa Universal: An International Journal of Chemistry, 2010; 1(2): 63-71.

37. Sawada Ayako, Kuroda Hiroyuki, Yoshida Taketoshi, Oyabu Takashi, Takenaka Kozaburo, Purification effects of Golden pothos and peace lily for indoor air- pollutants and its application to a real environment, Papers of technical meeting on chemical Sensor, journal of Institute of electrical engineers, Japan, 2004; 04(1)-13: 57-62.

38. Sriussadaporn C, Yamamoto K, Fukushi K, Simazaki D, Comparison of DNA damage detected by plant comet assay in roadside and non-roadside environments, journal of Mutational Research, 2003; 541(1-2): 31-44.

39. Heribert $S$, Hilgers $U$, Weidner $M$, Assimilation and metabolism of formaldehyde by leaves appear unlikely to be of value for indoor air purification, journal of Research of new phytologues, 2000; 147(2): 307-315.

40. Paulsen E, Stahl S P, Andersen KE, Immediate skin and mucosal symptoms from pot plants and vegetables in gardeners and greenhouse workers, Contact dermatitis, Journal of Health sciences and plants. 1998; 39(4): 166170.

41. Nihal C R, John W,David W M R, Use of antitranspirants under low-light environments to control transpiration of Epipremnum aureum leaves, Scientia Horticulturae, 43; (34): 307-312.

42. Seong $\mathrm{H} P$, Randomized clinical trials evaluating therapeutic influences of ornamental indoor plants in hospital rooms on health outcomes of patients recovering from surgery, a dissertation submitted in partial fulfillment of the requirements for the degree. Doctor of philosophy, Department of Horticulture, Forestry and Recreation Resources, College of Agriculture, journal of Green Pharmacy, 2006; 4: 21-32.

43. Khayyat $M$, Nazari $F$, Salehi $H$, Effects of Different Pot Mixtures on Pothos Epipremnum aureum Linden. And Andre 'Golden pothos' Growth and Development, American-Eurasian Journal of Agricultural \& Environmental Science, 2007; 2 (4): 341-348.

44. Luping QU, Jianjun C, Richard J, Henny, Yingfeng $H$, Russell D, Caldwell C A, Robinson, Thidiazuron promotes adventitious shoot regeneration from Pothos (Epipremnum aureum) leaf and petiole explants, 
international Journal of In Vitro Cellular Development and Biology of Plant,2001; 38: 268-271.

45. Huxley A, Griffiths M, Levy M, Grifiths M. Index of garden plants, The New Horticulture Society Dictionary of Gardening. $4^{\text {th }}$ ed. Vol. 1. London: Macmillan; 1994: 3353.

46. Ogundipe $\mathrm{O}$, Akinbiyi $\mathrm{O}$, Moody JO. Antimicrobial activity of selected ornamental plants. Niger Journal of National Products of Medicines, 1998; 2: 46-8.

47. Yang $\mathrm{H}$, Liu $\mathrm{Y}$, Phytoremediation on air pollution, the impact of air pollution on health, economy, environment and agricultural sources. International journal of technology; 2011: 281-94.

48. Douglass F, Indoor air quality planting healthier indoor air, News forum Environmental and Health Perspectives 2011; 119: A426-A427.

49. Xueng Z, Wang L, Hou H. Formaldehyde removal by potted plant-soil systems. Journal of Hazardous Material, 2011; 192: 314-318.

50. Wolverton BC, Johnson A, Bounds K. Interior landscape plants for indoor air pollution abatement, Final Report September NASA Stennis Space Center, MS; 1989: A 45- A 46

51. Davanzo F, Miaglia S, Perego S, Assisi F, Bissoli M, Borghini $\mathrm{R}$, et al. Plant poisoning: Increasing relevance, a problem of public health and education. North-Western Italy, Journal of Pharmacy Scientific Research, 2011; 3(7): 1338-43.

52. Palmer $M$, Betz $J M$,Goldfrank $L R$, Flomenbaum $N E$, Hoffman RS, Howland MA, Lewin NA, Nelson L. editors. Goldfrank's journal of Toxicological Emergencies. $8^{\text {th }}$ ed.; 2006: 1577-602.

53. Hung $\mathrm{CY}$, Sun $\mathrm{YH}$, Chen J, Darlington DE, Williams A, Burkey $\mathrm{KO}$, et al. Identification of a $\mathrm{Mg}$ protoporphyrin $\mathrm{IX}$ monomethyl ester cyclase homologue, EaZIP, differentially expressed in variegated Epipremnum aureum 'Golden Pothos' is achieved through a unique method of comparative study using tissue regenerated plants, Journal of Experimental Botany, 2010; 61: 1483-93.

54. Desai TS. Studies on thermoluminescence, delayed light emission and oxygen evolution from photosynthetic materials: UV effects, Journal of Photosynthetic Research, 1990; 25: 17-24.

55. Arathi KA, Lalitha $P$, Jayanthi $P$, Shubashini $K$ Sripathi, Phytochemical investigation of the Aerial roots of Pothos aurea (Linden ex Andre), journal $3^{\text {rd }}$ Indo Korean joint seminar on medicinal plant research, 2010; 5: 53-54

56. Patel, Roshan, Diuretic activity of leaves of Plectranthus ambionicum spring in male albino rats, the journal of Pharmacognostical research, 2010; 2.2: 86.

57. Dev, Protopaditya, Neuropharmacological properties of Milkiania scandens (linn ) Willd (astraceae), Journal of advanced Pharmaceutical technology and research, 2011; 214: 255

58. Gahlot K,Abid M, Sharma A, Pharmacological evaluation of Gelenium sempervirens rootsof CNS depressants activity, International Journal of Pharmaceutical research, 2011; 3.2: 693-697

59. Koga K, Iwasaki Y. Psychological and physiological effect in humans of touching plant foliage-using the semantic differential method and cerebral activity as Indicators, Journals of Physiology and Anthropology, 2013; 32: 7.

60. Wan Z, Wan M Z, Liliwirianis N, Kamaruzaman J, Screening of Epipremnum Sp., Syngramma alysmifolia, Thotea Sp. And Smilax Sp. For Antimicrobial Activity, journal of World Applied Sciences, 2010; 8 (7): 889-891.

Source of Support: The author(s) received no financial support for the research, authorship, and/or publication of this article.

Conflict of Interest: The author(s) declared no potential conflicts of interest with respect to the research, authorship, and/or publication of this article.

For any question relates to this article, please reach us at: editor@globalresearchonline.net New manuscripts for publication can be submitted at: submit@globalresearchonline.net and submit_ijpsrr@rediffmail.com 